\title{
Prevention of recurrent venous ulceration
}

\author{
Maria T. Szewczyk ${ }^{1,2}$, Justyna Cwajda-Białasik ${ }^{1}$, Arkadiusz Jawieńn \\ ${ }^{1}$ Department of Surgery Nursing, Ludwik Rydygier Collegium Medicum in Bydgoszcz, Nicolaus Copernicus University in Torun, Poland \\ Head: Maria T. Szewczyk MD, PhD \\ 2Department of Surgery, Ludwik Rydygier Collegium Medicum in Bydgoszcz, Nicolaus Copernicus University in Torun, Poland \\ Head: Prof. Arkadiusz Jawień MD, PhD
}

Postep Derm Alergol 2012; XXIX, 4: 308-312

DOI: 10.5114 /pdia.2012.30472

\begin{abstract}
Conservatively treated venous ulceration should be considered a chronic condition, characterized by consecutive periods of exacerbation, healing, and recurrence. Healing of venous ulceration can be considered a therapeutic success, particularly in the case of chronic wounds. The skin, weakened by many years of venous hypertension, becomes more susceptible to destruction, mechanical injuries, and the progression of the disease. Consequently, the application of tertiary prevention becomes the basis for the prevention of venous hypertension, which can potentially lead to the reactivation of inflammation, trophic lesions, and destruction of tissues.
\end{abstract}

Key words: venous ulceration, recurrent ulceration, prevention.

\section{Introduction}

The results of epidemiological studies reveal high recurrence rates of venous ulcerations, approximately $26-70 \%$ [1-3]. More than one half of patients (54\%) experience recurrent ulceration $[4,5]$. According to on of the studies [6], about $26 \%$ of ulcerations recur within the initial 12 months following the completion of the therapy. Patients referred to regular check-ups and placed under constant supervision of specialists can markedly prolong the period of remission or even avoid recurrent ulceration [7, 8]. Continuation of compression therapy is postulated to be the most efficient method of prevention [9]. Experts in the field unambiguously point out to the high effectiveness of this method in the prevention of recurrent ulceration [10-13]. Pharmacological therapy plays a vital supportive role and out of many drugs, efficacy of only three (pentoxifylline, sulodexide and diosmine) is confirmed by studies [13].

\section{Why does recurrent ulceration develop?}

One study investigating the causes of recurrent ulceration highlighted the role of inadequate cooperation of the patient and the resultant discontinuation of compression therapy following healing of the wound [14]. It was revealed that patients' motivation and attitude towards further treatment was defined to a large extent by their insufficient knowledge and understanding of disease fundamentals [15-17]. One can hardly expect patients to become involved in their treatment if they are unaware of its necessity or regard themselves as healthy. The study [18] revealed that patients with healed ulceration are aware of the risk of potential recurrences, but instead of assigning significance to the lack of compression associate it with the influence of other factors, such as injury or the natural history of the disease - beyond any control. Most of them believe that wearing compressive stockings is not necessary or even redundant as it does not provide full protection, simultaneously being burdensome and uncomfortable. Patients admitted that even prior to wound healing they found the compression therapy unwarranted and not fully understandable. Trusting the knowledge and experience of nurses who took care of them, they still followed their advice and recommendations, at least until the wound healed. Nevertheless, patients neither preferred to continue the treatment nor were eager to attend systematic follow-up visits. From the patients' point of view, these activities were required only if ulceration recurred and/or the symptoms (e.g. pain) exacerbated.

Other risk factors of recurrence include co-existing deficiency of the muscle pump - dysfunction and stiffness of the ankle joint, the lack of therapies supporting venous return (e.g. exercises and proper body stature), obesity, diet, and tobacco smoking [13, 15, 19-21].

Address for correspondence: Maria T. Szewczyk MD, PhD, Department of Surgery, Ludwik Rydygier Collegium Medicum, 75 Ujejskiego, 85-168 Bydgoszcz, Poland, phone: +48 5236552 32, fax: +48 52365 57 82, e-mail: mszewczyk@cm.umk.pl 


\section{Secondary prevention}

Application of compression therapy and conservative treatment solely during the period of active ulceration, even if reflected by complete healing of the wound, does not guarantee a persistent effect and should be continued on a constant basis in the majority of cases. Effective causative treatment involving the continuous compression therapy or alternative methods, enabling the reduction of venous hypertension-related consequences, constitutes the basis of post-treatment prevention of ulceration [12, 13, 22-24].

The preventive measures include [13, 22, 25]:

- Continuation of causative treatment (compression therapy) or surgical intervention.

- The effects of superficial venous surgery in venous ulceration healing are also supported by a recent ESCHAR trial, in which the efficacy of compression therapy alone vs. compression therapy and surgery was compared. After 6 months' follow-up, in both groups the rate of healed ulcerations was $65 \%$. In turn, after 12 months, the rate of recurrent ulcerations in a compression and surgery group was $12 \%$ while in the compression alone group $-28 \%$. This difference was statically significant [25].

- Continuation of the supportive therapy elements, such as kinesiotherapy and physiotherapy [19].

- Regular check-ups at the specialist clinic [13, 21].

- Education of patients enabling them to understand the fundamentals of their disease and the necessity of continuous treatment [21].

\section{Primary therapy}

The symptoms of venous insufficiency can be controlled with invasive methods or by means of conservative therapy. The former approach involves surgical procedures such as the correction of hemodynamic disorders, or less invasive vascular sclerotherapy and obliteration [26-28]. The efficiency of various methods is variable, depending on the technique of surgery and the type and extent of venous insufficiency. The rate of recurrences documented 12-18 months post-surgery ranges between $6 \%$ and $58 \%$ [26]. In contrast, there are no data with regard to the long-term benefits - the latter is disputed among dermatologists and surgery specialists and constitute an unanswered question for further research $[12,13,22]$.

Similarly, there is no systematic evidence of the recurrence rates resulting from compressive therapy or the lack of such treatment. Nevertheless, the experts' opinions are unanimous: progressive compression is an accepted and recommended treatment for all patients with healed ulceration [11-13, 21, 22]. Compressive stockings are preferred in the secondary prevention. Although the results of previous trials did not confirm their superiority over other compressive systems (and do not promote either method), in patients' opinion the stockings are more comfortable and easier to wear than bandages, do not require any special skills, and can be donned by the patients themselves [21]. They are selected and prescribed by a properly trained individual, who adjusts the class and type of compression to the cardiovascular system capacity (the value of ankle-brachial index, $A B I$ ) and tolerance of the patient. Since low values of pressure generated by elastic stockings, used among others for perioperative prevention, do not provide a sufficient therapeutic level of compression, the highest possible class of compression is required, optimally $40 \mathrm{~mm} \mathrm{Hg}$ at the ankle level. If the patient does not tolerate high compression for various reasons and complains about discomfort, or has difficulties with putting on the stockings, it is better to recommend the compression with lower pressure (e.g. $30 \mathrm{~mm} \mathrm{Hg}$ ) rather than to discontinue this treatment. It should be ascertained beforehand if patient-reported difficulties can be eliminated; sometimes changing the brand and type of stockings can be associated with considerable benefits and improve patient cooperation more effectively than a reduction in compression [13, 21, 29]. The type of compression, thickness of the material and its physical characteristics are modulated by many factors, such as elastomer properties, structure of fibers, and the method of manufacturing. The addition of natural rubber increases the tension of the material and reduces its elasticity, improving the durability of the stockings. Synthetic products, described as "fine quality" are thinner and more elastic; moreover, they are characterized by shorter durability [13, 15, 29].

The stockings offer elastic compression and should be worn during the day when the venous return is hindered by the patient's position. Consequently, they should be put on in the morning and taken off before going to bed at night, preventing complications and potential hyperemia. Depending on the type of fibers and durability of the material, stockings should be exchanged every 6 months in accordance with the manufacturer's recommendations $[12,13,29]$.

\section{Supportive therapies}

Chronic venous insufficiency and ulceration, as well as post-treatment cicatrix can be associated with ankle joint abnormalities - its reduced mobility affecting plantar and dorsal flexure of the foot and associated deficiency of muscle-articular pump, a mechanism that stimulates the venous return together with the vascular-valvular system regulating the value of hydrostatic pressure [19, 20].

Dysfunction of the pump can precede the development of ulceration and constitute one of the causative factors of venous hypertension. Moreover, it is of a secondary character, resulting from the influence of chemical mediators that initiate the inflammation of surrounding tissues. This is reflected by their edema and pain, 
promoting cicatrization and strain on the Achilles tendon. Additionally, it reduces the mobility of the ankle joints, consequently limiting the physical activity of patients $[13,21,29,30]$.

The aim of supportive therapy is to prevent these disorders, as well as to attenuate their potential consequences. Similarly to primary therapy, the supportive therapy is aimed at improving hemodynamics and stimulating venous flow. Patients should be motivated to increase their activity and perform exercises that stimulate calf muscles. They should be offered ankle joint specific exercises - simple exercises that do not require any advanced skills. Training the patients to walk correctly should also be emphasized. Many patients are unaware of the role played by the alternate flexure and extension of foot in the stimulation of venous circulation. They tiptoe or do not perform the entire range of movement in the dorsal and plantar part of the foot. They are afraid of pain associated with overcoming present limitations as well as with reduced joint mobility. Sometimes, patients themselves are unconsciously hindering the correct way of walking by improper selection of shoes - too rigid, limiting mobility, or with too high heels that immobilize the calf joints. Furthermore, patients should be instructed in the selection of proper activity type and choice of clothing [13, 19-22, 31, 32].

Patients should be advised to assume the position promoting venous circulation while standing motionless or sleeping. They should lay down with their lower limbs elevated above the level of the heart or in a slightly elevated bed (e.g. with the footboard elevated by about $20-30 \mathrm{~cm}$ ). Long periods of standing should be interrupted by several minutes of rest with elevated legs or simple, isometric or active exercises of the calf muscles, such as alternate tiptoeing and standing on the base of the foot, or walking on the spot $[13,21,22]$.

\section{Follow-up visits}

Systematic follow-up of patients with healed crural ulceration is equally important in the prevention of recurrence as in the therapy of active ulceration. Treatment of the patient should be continued until the cause of wound development is eliminated, that is until the resolution of chronic venous insufficiency. Patients for whom this is not possible, experience long-term, or seemingly endless, treatment in specialized healthcare units. Posthealing follow-up enables cardiovascular monitoring and increases the chances of rapid and effective intervention in the case of progressive impairment or the loss of skin continuity [21, 30, 31, 33].

Similar to the period of active ulceration, follow-up visits should take place every 3 months on average and include the repeated physical examination of limbs and the inspection of the skin status. Additionally, the anklebrachial index and the degree of patient's cooperation during compression therapy and pharmacotherapy should be determined in the case of older individuals $[13,21$,
24, 30]. Patient's knowledge and skills should be assessed along with the ability to put on the stockings by themselves. The proper selection of a particular stocking should be verified and adjusted to patient's tolerance, mood, and financial possibilities. Depending on the manufacturer's recommendations, the exchange of stockings and purchase of a new pair should be recommended every 6 months in order to ensure sufficient supply and possibility of washing depending on patient's needs. Prescribing a new pair of stockings should be preceded by measuring patient's limbs [29, 31]. Specialist consultation and detailed diagnostic examination are required in the case of complications: exacerbation of symptoms of primary disease (chronic venous insufficiency), development of new symptoms, or ulceration recurrence [13, 21, 24, 30].

\section{Education of the patient}

Systematic cooperation with the patient can improve the therapeutic outcomes to a large degree and reduce rates of recurrence. The quality of cooperation is modulated by patient's motivation and attitude to proposed treatment. Patients who do not understand the fundamentals of venous insufficiency and are unaware of ulceration etiology will not be entirely convinced of the validity and effectiveness of compression therapy. Patient's cooperation and motivation can be improved by including education in the management and treatment of ulceration; thus, increasing their involvement and active participation in the therapeutic process $[13,21,31,34]$.

The following issues should be addressed with particular emphasis during the process of education and providing the ulceration patients with knowledge and skills required for post-healing continuation of treatment $[9,18$, 20, 21, 24, 31, 32, 35]:

- Compressive stockings (worn during the day and taken off at night) should be used continuously. Therapeutic compression used successfully during a period of active ulceration should be continued post-healing to reduce the negative consequences of the disease and to prevent potential recurrence.

- An initial feeling of discomfort associated with wearing the stockings can be eliminated by changing the product's brand or reducing the class of compression.

- Patients having difficulties with putting on the stockings themselves can be offered supportive devices or prescribed zip-up stockings that are easier to wear.

- The prescribed pair of compressive stockings should be exchanged every 6 months in accordance with the manufacturer's recommendations.

- Avoiding injuries and daily control of the skin status will facilitate early detection of potential injury/irritation and rapid intervention. Patients should be made aware that venous disorders are reflected by a deteriorated condition of the skin and its protective function, increasing its susceptibility and risk of non-healing wounds. 
- Exercises improving the mobility of the ankle joint and the function of muscle pump play an important role in the prevention of progressive disease and disorders. Consequently, the patients should be motivated to perform simple exercises, walking, and sports, if possible.

- Patients should have proper, comfortable shoes with short heels (up to 2-3 cm) for performing motor activities and other types of physical activity. Shoes should neither limit patient's movements nor flexibility of the ankle joints.

- Proper body position at rest reduces venous hypertension and potential limb edema; therefore, patients should be motivated to rest in the supine position with lower limbs elevated above the level of the heart. The footboard should be elevated by approximately $20-30 \mathrm{~cm}$ and a footstool should be used while seated.

- Low levels of physical activity, prolonged sitting/standing, weightlifting, chronic constipation, tobacco smoking, and obesity represent negative factors that enhance symptoms of venous insufficiency; therefore, patients should be encouraged and motivated to lifestyle modification $[15,18,20]$.

\section{Conclusions}

Various preventive measures should be addressed with regard to the patients who are at risk of ulceration, in the course of their treatment, and post-healing of venous ulceration. Patients should be encouraged and motivated to employ preventive measures. Although these will neither eliminate the disease nor cause its complete regression, they can prevent its progression, reduce symptoms and complaints, and prevent serious consequences of CVI and recurrent ulceration. Moreover, the knowledge of preventive methods can constitute the starting point for other health-promoting activities.

\section{References}

1. Mayberry J, Moneta G, Taylor L, Porter J. Fifteen-year results of ambulatory compression therapy for chronic venous ulcers. Surgery 1991; 109: 575-81.

2. Dinn E, Henry M. Treatment of venous ulceration by injection sclerotherapy and compression hosiery: a five-year study. Phlebology 1992; 7: 23-6.

3. Moffatt C, Franks $P$. The problem of recurrence in patients with leg ulceration. J Tissue Viabil 1995; 5: 64-6

4. Callam MJ, Ruckley CV, Harper DR, Dale JJ. Chronic ulceration of the leg: extent of the problem and provision of care. BMJ (Clin Res Ed) 1985; 290: 1855-6.

5. Callam MJ, Harper DR, Dale JJ, Ruckley CV. Chronic ulcer of the leg: clinical history. BMJ (Clin Res Ed) 1987; 294: 1389-91.

6. Nelson EA, Bell-Syer SEM, Cullum NA. Compression for preventing recurrence of venous ulcers. Cochrane Database Syst Rev 2000; 4: CD002303.

7. Poore S, Cameron J, Cherry G. Venous leg ulcer recurrence; prevention and healing. J Wound Care 2002; 11: 197-9.
8. Moffat CJ, Dorman MC. Recurrence of leg ulcers within a community ulcer service. J Wound Care 1995; 4: 57-61.

9. Nelson EA, Harper, DR, Prescott RJ, et al. Prevention of recurrence of venous ulceration: randomized controlled trial of class 2 and class 3 elastic compression. J Vasc Surg 2006; 44: 803-8.

10. Partsch H, Clark M, Bassez S, et al. Measurement of lower leg compression in vivo: recommendations for the performance of measurements of interface pressure and stiffness: consensus statement. Dermatol Surg 2006; 32: 224-32.

11. Partsch H, Flour M, Coleridge-Smith PD. Consensus statement. Indications for compression therapy in venous and lymphatic disease. Int Angiol 2008; 27: 193-219.

12. Vin F, Benigini JP. Compression therapy. International Consensus Document Guidelines according to scientific evidence. Int Angiol 2004; 3: 317-45.

13. Jawień A, Szewczyk MT, Kaszuba A, et al. Wytyczne Polskiego Towarzystwa Leczenia Ran w sprawie gojenia owrzodzeń żylnych goleni. Leczenie Ran 2011; 8: 35-56.

14. Nelzen O, Bergqvist D, Lindhagen A, Hallbook T. Chronic leg ulces: an underestimated problem in primary Heath care among elderly patients. J Epidemiol Community Health 1991; 45: 184-7.

15. Moffat C, O'Hare L. Graduated compression hosiery for venous leg ulceration. J Wound Care 1995; 4: 459-62.

16. Alexander House Group Consensus Paper on Venous Leg Ulcers. Phlebology 1992; 7: 48-58.

17. Harker J. Influences on patient adherence with compression hosiery. J Wound Care 2000; 9: 379-82.

18. Flaherty $E$. The views of patients living with healed venous leg ulcers. Nursing Standard 2005; 19: 78-89.

19. Szewczyk MT, Jawień A, Cwajda-Białasik J, et al. Randomized study assessing the influence of supervised exercises on ankle joint mobility in patients with venous leg ulcerations. Arch Med Sci 2010; 6: 956-63.

20. Kan YM, Delis KT. Hemodynamic effects of supervised calf muscle exercise in patients with venous leg ulceration: a prospective controlled study. Arch Surg 2001; 136: 1364-9.

21. SIGN: Management of chronic venous leg ulcers: A National Clinical Guideline. Scottish Intercollegiate Guidelines Network 2010; 26: 1-29.

22. Subcommittee of the European Dermatology Forum. Guidelines for Diagnostics and Treatment of Venous Leg Ulcers. Expiry date:3/2011 http://www.euroderm.org/edf/images/stories/guidelines/guideline_venous_leg_ulcers.pdf - data pobrania 1.12. 2011.

23. Nelson EA, Mani R, Vowden K. Intermittent pneumatic compression for treating venous leg ulcers. Cochrane Database Syst Rev 2008; 2: CD001899.

24. Collins L, Seraj S. Diagnosis and treatment of venous ulcers. Am Fam Physician 2010; 81: 989-96.

25. Barwell JR, Davies CE, Deacon J, et al. Comparison of surgery and compression with compression alone in chronic venous ulceration (ESCHAR sudy): randomised controlled study. Lancet 2004; 363: 1854-9.

26. Cavezzi A, Frullini A, Ricci S, Tessari L. Treatment of varicose veins by foam sclerotherapy: two clinical series. Phlebology 2002; 17: 13-8.

27. Cabrera J, Redondo P, Becerra A, et al. Ultrasound-guided injection of polidocanol microfoam in the management of venous legs ulcers. Arch Dermatol 2004; 140: 667-73.

28. Cabrera J, Cabrera J Jr, Garcia-Olmedo MA. Sclerosants in microfoam. Int Angiol 2001; 20: 322-9.

29. O'Hare L. Scholl compression hosiery in the management of venous disorders. Br J Nurs 1997; 6: 391-4. 
30. Nicolaides AN. Investigation of chronic venous insufficiency. A consensus statement. Circulation 2000; 102: 126-63.

31. Jawień A, Szewczyk MT. Kompresjoterapia. Termedia, Poznań 2009.

32. Benbow M, Burg G, Comacho Martinez F. Guidelines for the outpatient treatment of chronic wounds and burns. Blackwell Science, Berlin-Vienna 1999; 12-21.

33. Sopata M, Tomaszewska E, Machyńska-Bućko Z, KotlińskaLemieszek A. Modern methods of conservative treatment of pressure ulcers. Postep Derm Alergol 2012; 29: 40-6.

34. Rup E, Skóra M, Krzyściak P, Macura AB. Distribution of Malassezia species in patients with atopic dermatitis - quality assessment. Postep Derm Alergol 2011; 28: 187-90.

35. O'Meara S, Cullum NA, Nelson EA. Compression bandages and stockings to aid the healing of venous leg ulcers Cochrane Database Syst Rev 2009: 1: CD000265. 